\title{
Parameters Affecting the Precipitation of Al Phases from Aluminate Solutions of the Pedersen Process: The Effect of Carbonate Content
}

\author{
Danai Marinos $^{1}\left[\right.$ - Michail Vafeias ${ }^{1} \cdot$ Dimitris Sparis $^{1} \cdot$ Dimitris Kotsanis $^{1} \cdot$ Efthymios Balomenos $^{1,2} \cdot$ Dimitris Panias $^{1}$
}

Received: 17 March 2021 / Accepted: 7 July 2021 / Published online: 29 July 2021

(c) The Author(s) 2021, corrected publication 2021

\begin{abstract}
Leaching experiments were performed in calcium aluminate slag with a high-sodium carbonate adaptation of the Pedersen process. A theoretical thermodynamic study of the pregnant leaching solution was conducted to specify the thermodynamically favored species that exist within. Using the HSC 9.0 software, a carbonation process simulation (neutralization of the aluminate solution with $\mathrm{CO}_{2}$ gas) was simulated. Laboratory carbonation experiments were conducted to verify the theoretical predictions. According to the thermodynamic study, at temperatures below $50{ }^{\circ} \mathrm{C}$ gibbsite precipitates in the first stages of carbonation and then is transformed to dawsonite. Temperatures over $65^{\circ} \mathrm{C}$ favor the direct precipitation of dawsonite. The same route (thermodynamic analysis, carbonation simulation, and experimental verification) was followed by a synthetic solution containing lower amount of sodium carbonate to prove that dawsonite precipitation occurred as a result of the high free carbonate content, to investigate the effect of temperature and to precipitate alumina hydrate phases.
\end{abstract}

\section{Graphical Abstract}

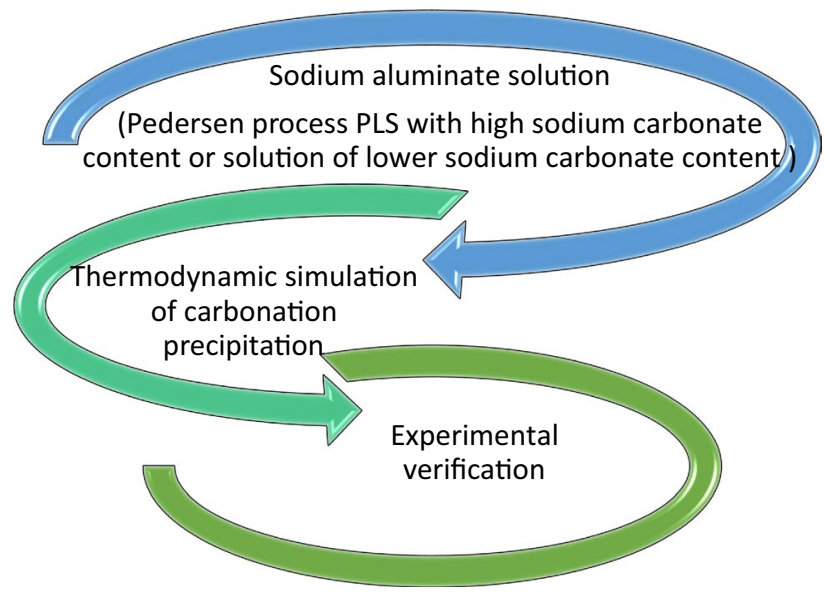

Keywords Carbonation precipitation $\cdot$ Sodium aluminate solution $\cdot$ Thermodynamic simulation $\cdot$ Pedersen process · Alumina hydrates

The contributing editor for this article was Yiannis Pontikes.

Danai Marinos

dmarinou@metal.ntua.gr

Extended author information available on the last page of the article

\section{Introduction}

The Pedersen process is a process for the production of cast iron and metallurgical alumina from bauxites and other Alcontaining resources [1]. Originally applied on an industrial scale in Norway, it consists of two stages. The first stage is 
a reductive smelting of bauxite with lime, leading to the production of metallic iron and a calcium aluminate (CA) slag. In the second stage, the CA slag is hydrometallurgically treated with a $\mathrm{Na}_{2} \mathrm{CO}_{3}$ solution, a process leading, in principle, to the extraction of $\mathrm{Al}$ in the pregnant leaching solution (PLS) and a calcium carbonate residue. Finally, the PLS undergoes a neutralization precipitation process with carbon dioxide gas, to produce alumina hydrates. These will undergo a calcination process to produce metallurgical grade alumina.

Although the Pedersen process was abandoned in 1969, studying the process from the perspective of sustainability and circular economy, certain attractive features stand out [2]. Firstly, it promises a complete utilization of bauxite ores, even some rejected by the Bayer Process [3], since it aims at the production of iron and alumina. Moreover, the hydrometallurgical conditions applied are moderate and, most importantly, the issue of bauxite residue is eliminated as, in its place, a calcium-based residue is produced in the leaching stage with potential applications (e.g., in the construction industry or agricultural sector).

Of the two metallurgical stages of the Pedersen Process, the most challenging is the hydrometallurgical one and especially the precipitation of the alumina hydrates with carbon dioxide gas. Detailed knowledge of this stage of the Pedersen Process is virtually non-existent in literature. The only available resources are the patents of the Pedersen process; however, the legal nature of these documents provides fragmented and vague information. Initially, it is stated that carbon dioxide precipitation is feasible but not effective. Later, it is claimed that, by adding sodium hydroxide, to increase alkalinity and alumina hydrate seed, precipitation can be performed according to the principles of the Bayer precipitation stage. Spent solution after precipitation is then re-carbonated with carbon dioxide gas and recycled to the leaching stage.

Besides being mentioned in the Pedersen process [4, 5], precipitation by carbonation is highly attractive to alumina refineries that operate based on sintering processes, since the neutralized product of sodium carbonate can be directly recycled. Such is the case in refineries in Russia and China that have poor grade diasporic bauxites or nepheline [6, 7]. The ore is mixed with $\mathrm{Na}_{2} \mathrm{CO}_{3}$ and is sintered in temperatures higher than $1000{ }^{\circ} \mathrm{C}$ to form sodium aluminate which is highly soluble in water. Out of such aluminate solutions, alumina hydrates are precipitated by carbonation [8]. The carbonation process is carried out in the temperatures of $70-80{ }^{\circ} \mathrm{C}$ and duration times ranging from 5 to $8 \mathrm{~h}$ [9]. Lee et al. [10] showed that higher temperatures $\left(70{ }^{\circ} \mathrm{C}\right)$ favor the formation of gibbsite, while lower temperatures (room temperature) favor the formation of bayerite.

In general, precipitation by carbonation presents some drawbacks, compared to Bayer precipitation. It is stated that alumina hydrates thus produced are of inferior quality due to the concentration of impurities [11], such as silica, and the inappropriate particle size and morphology $[7,11]$.

The focus of the current work is the link between the leaching and the precipitation operations of the hydrometallurgical side of the Pedersen process. In theory, the PLS enters the precipitation stage, where carbon dioxide gas is added to lower the $\mathrm{pH}$ of the solution and precipitate aluminum as aluminum hydroxide. Firstly, carbon dioxide is absorbed in the sodium aluminate solution according to reactions (1) and (2). Then, the alkaline solution is gradually neutralized, followed by the decomposition of the aluminate ion, leading to the precipitation of aluminum hydroxide according to reaction (3). The overall precipitation reaction is shown in reaction (4).

$\mathrm{CO}_{2}+\mathrm{H}_{2} \mathrm{O}=\mathrm{HCO}_{3(\mathrm{aq})}^{-}+\mathrm{H}_{(\mathrm{aq})}^{+}$

$\mathrm{HCO}_{3(\mathrm{aq})}^{-}=\mathrm{CO}_{3(\mathrm{aq})}^{-2}+\mathrm{H}_{(\mathrm{aq})}^{+}$

$\mathrm{Al}(\mathrm{OH})_{4(\mathrm{aq})}^{-}=\mathrm{Al}(\mathrm{OH})_{3(\mathrm{~s})} \downarrow+\mathrm{OH}_{(\mathrm{aq})}^{-}$

$\mathrm{NaAl}(\mathrm{OH})_{4}+\frac{1}{2} \mathrm{CO}_{2}=\mathrm{Al}(\mathrm{OH})_{3(\mathrm{~s})} \downarrow+\frac{1}{2} \mathrm{Na}_{2} \mathrm{CO}_{3}+\frac{1}{2} \mathrm{H}_{2} \mathrm{O}$

To study these mechanisms, leaching tests in a CA slag of modeled composition were performed and a PLS of chosen composition was selected based on maximum dissolved Al. This PLS, however, had a high concentration of free (unreacted) sodium carbonate, i.e., it is of a composition that has not been studied before in a carbonation process. Thus, to understand the precipitation behavior of this solution, a thermodynamic analysis was performed with the software HSC 9.0 to assess the phases predicted to precipitate from such solutions under a carbonation process like the original Pedersen Process. Afterward, experiments were performed to confirm the thermodynamic predictions. The same route was followed for a theoretical PLS of lower sodium carbonate content.

\section{Materials and Methodology}

A series of leaching tests were conducted on a CA slag of modeled composition. The powder XRD analysis of the slag and the identified phases are shown in Fig. 1. The main phases identified are the calcium aluminates $\mathrm{CA}, \mathrm{C}_{12} \mathrm{~A}_{7}$, and $\mathrm{C}_{5} \mathrm{~A}_{3}$. In addition, a graphite peak is detectable, originating probably from the graphite crucible used as the container of solids for the bauxite smelting process. 


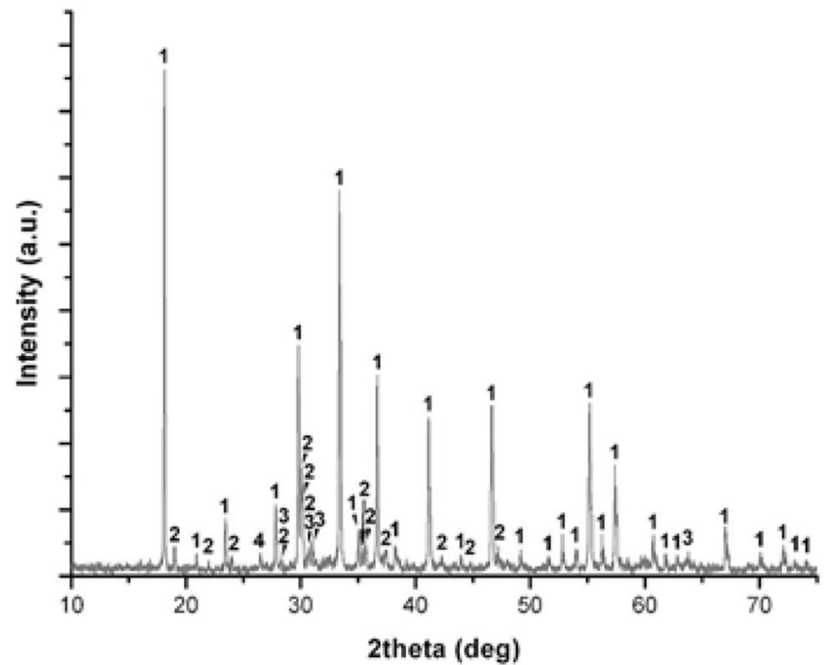

Fig. 1 Powder XRD analysis of the calcium aluminate slag under consideration. Identified phases are as follows: (1) $12 \mathrm{CaO} \cdot 7 \mathrm{Al}_{2} \mathrm{O}_{3}$ (mayenite), (2) $\mathrm{CaO} \cdot \mathrm{Al}_{2} \mathrm{O}_{3} \quad$ (monocalcium aluminate), (3) $5 \mathrm{CaO} \cdot 3 \mathrm{Al}_{2} \mathrm{O}_{3}$ (pentacalcium trialuminate), and (4) $\mathrm{C}$ (Graphite)

Table 1 Average compositions of aluminate solutions used in precipitation tests

\begin{tabular}{lll}
\hline Species & \multicolumn{2}{l}{ Concentration } \\
\cline { 2 - 3 } & $\begin{array}{l}\text { PLS } \\
(\mathrm{g} / \mathrm{L})\end{array}$ & $\begin{array}{l}\mathrm{LCS} \\
(\mathrm{g} / \mathrm{L})\end{array}$ \\
\hline $\mathrm{Na}_{2} \mathrm{CO}_{3}$ & 159 & 21 \\
$\mathrm{NaOH}$ & 20 & 15 \\
$\mathrm{NaAl}(\mathrm{OH})_{4}$ & 35 & 34 \\
$\mathrm{Na}_{2} \mathrm{SiO}_{3}$ & 1.22 & 0.24 \\
\hline
\end{tabular}

According to earlier research conducted by the U.S. Bureau of Mines on a pilot scale for a modification of the Pedersen Process [12], more concentrated aluminate solutions can be produced if higher $\mathrm{Na}_{2} \mathrm{CO}_{3}$ concentrations are applied to the leaching stage, with a cost in the overall leaching efficiency, which declines progressively. Our work confirmed these findings as it was found that the highest $\mathrm{Al}_{2} \mathrm{O}_{3}$ extraction $(\approx 70 \%)$ for a $5 \% S / L$ ratio was achieved in the following conditions: $90^{\circ} \mathrm{C}$, stirring rate of $300 \mathrm{rpm}$, leaching solution of $120 \mathrm{~g} / \mathrm{L} \mathrm{Na} \mathrm{Na}_{2}\left(92 \%\right.$ as $\mathrm{Na}_{2} \mathrm{CO}_{3}, 8 \%$ as $\left.\mathrm{NaOH}\right)$, and a mean particle size $\mathrm{D}(\mathrm{V}, 0.5) \approx 90 \mu \mathrm{m}$. The concentration of the PLS in $\mathrm{Al}_{2} \mathrm{O}_{3}$ was $16 \mathrm{~g} / \mathrm{L}$ and $416 \mathrm{ppm}$ of $\mathrm{SiO}_{2}$.

For the carbonation precipitation tests conducted in this research, two synthetic starting solutions of different compositions were chosen. The first solution is based on the pregnant leaching solution (PLS) from the leaching of CA slags with an excess of $\mathrm{Na}_{2} \mathrm{CO}_{3}$ and therefore it contains a high amount of free $\mathrm{Na}_{2} \mathrm{CO}_{3}$ as is seen in Table 1. This composition was used as the basis for the thermodynamic analysis and the precipitation experiments.
The composition of the second solution (low carbonate solution-LCS) simulates the outcome of a two-stage leaching process as the one applied both in the original Pedersen process and the modified one employed by the U.S. Bureau of Mines [12]. In a two-stage leaching circuit fresh slag and fresh leaching solution move counter-currently. Fresh leaching solution enters the reactor of the second leaching stage (called the half-saturation stage), where it leaches a slag that has already been partially leached with a previous batch of solution in the first stage. Correspondingly, fresh slag enters the reactor of the first leaching stage (also called the saturation stage) and is being leached by a solution coming from the half-saturation stage. As the fresh slag contains unreacted calcium sites (on the surface of calcium aluminates), this stage both desilicates and removes excess carbonates from the solution. So, the second synthetic solution is based on the PLS expected to overflow from the saturation stage of the modified Pedersen process, on which our work was also based, for which the free $\mathrm{Na}_{2} \mathrm{CO}_{3}$ content is the lowest possible (Table 1).

For the thermodynamic simulation of the carbonation process, the HSC Chemistry 9.0 software by Outotec was utilized with the module Equilibrium composition. To better simulate the carbonation process, $22.22 \mathrm{~mol}$ of water solution ( $400 \mathrm{~mL}$ volume) were considered to balance the solution, and to simulate the $\mathrm{CO}_{2}$ addition, $0.0089 \mathrm{~mol}$ of $\mathrm{CO}_{2}$ gas was added $(200 \mathrm{~mL} / \mathrm{step})$. The species considered were as follows: (1) all aluminum aqueous hydroxo-, monoand poly-nuclear, as well as carbonato- complexes, (2) all sodium species, (3) all silicon species, (4) sodium aluminosilicate phases such as nepheline were considered to simulate Si-undersaturated aluminosilicates, as well as several zeolite compounds such as analcime, natrolite, etc. and (5) carbonated solid phases such as dawsonite $\left[\mathrm{NaAlCO}_{3}(\mathrm{OH})_{2}\right]$ and cancrisilite. Hydroxy sodalite and Na-cancrinite were not considered as they are absent from the software database. Aluminum in sodium aluminate solutions, in the aqueous phase is known to exist as $\mathrm{Al}(\mathrm{OH})_{4}{ }^{-}[13] . \mathrm{Al}(\mathrm{OH})_{2}{ }^{-}$was also considered for the thermodynamic analysis since it can exist along with $\mathrm{Al}(\mathrm{OH})_{4}{ }^{-}$ion in dense sodium aluminate solutions [14]. The only gas phase considered was $\mathrm{CO}_{2}$, since this is the reacting phase.

Turning to the experimental verification of the theoretical modeling, all synthetic aluminate solutions for the precipitation tests were prepared with reagent grade $\mathrm{NaOH}$ (pellets), $\mathrm{Na}_{2} \mathrm{CO}_{3}$ (anhydrous powder), $\mathrm{Al}(\mathrm{OH})_{3}$ (gibbsite) provided by MYTILINEOS S.A. alumina refinery, and $\mathrm{SiO}_{2}(99.5 \%$ purity). The reagents were mixed with $400 \mathrm{~mL}$ of deionized water at $160{ }^{\circ} \mathrm{C}$ for $2 \mathrm{~h}$ in an autoclave until completely dissolved. The precipitation experiments took place in a modified Parr autoclave system, with a specially made Teflon lid. All the carbonation experiments were performed under atmospheric pressure conditions. For each test, $400 \mathrm{~mL}$ of 
synthetic aluminate solution were introduced into the reactor and heated to the desired temperature. Carbon dioxide gas (99.995\% purity) was then introduced at a constant flow (200 $\mathrm{cm}^{3} / \mathrm{min}$ ) controlled by a flowmeter (Omega FMA series). Introducing the gas into the inlet signified the start of the experiment. $\mathrm{pH}$ measurements were taken per minute and the stirring rate remained constant at $150 \mathrm{rpm}$. At the end of each experiment the solution was filtered and analyzed with Atomic Absorption Spectroscopy (AAS), (PinAAcle 900T, Perkin Elmer). The solid precipitates were dried at $110{ }^{\circ} \mathrm{C}$ for $24 \mathrm{~h}$ and then characterized by X-ray diffraction analysis (XRD) on an X'Pert Pro diffractometer (PANalytical) with $\mathrm{CuKa}$ radiation (diffraction patterns were recorded between 10 and $70^{\circ} 2 \theta$, in $0.02^{\circ}$ steps and $2 \mathrm{~s}$ per step) and Fourier-transform infrared spectroscopy (FTIR) was carried out employing a PerkinElmer Spectrum 100 spectrometer, equipped with a diamond attenuated total reflectance (ATR) accessory (spectra were acquired in transmittance mode, from 4000 to $650 \mathrm{~cm}^{-1}$ with a resolution of $4 \mathrm{~cm}^{-1}$ and 16 scans per spectrum).

\section{Results and Discussion}

\section{Thermodynamic Analysis of PLS}

The Al speciation diagram of the PLS (Fig. 2a) shows that it is supersaturated in $\mathrm{Al}$. At temperatures below $50{ }^{\circ} \mathrm{C}$, gibbsite is spontaneously precipitated, whereas, at temperatures over $65^{\circ} \mathrm{C}$, dawsonite is spontaneously precipitated. This phenomenon can be attributed to the values of $k_{\mathrm{sp}}$ of both solids at different temperatures. As it can be seen in Fig. 2b, at temperatures below $50{ }^{\circ} \mathrm{C}$, the $k_{\mathrm{sp}}$ of gibbsite is lower than that of dawsonite. Over $65^{\circ} \mathrm{C}$, the values are reversed. The prediction that these two phases can precipitate out of the PLS at different temperatures formed the backbone for the simulation in HSC 9.0. To be more precise, carbonation was studied for two temperature values, one below $50{ }^{\circ} \mathrm{C}$ and one over $65{ }^{\circ} \mathrm{C}$. The values chosen were $40{ }^{\circ} \mathrm{C}$ and 80 ${ }^{\circ} \mathrm{C}$, respectively.

\section{Carbonation Simulation of PLS at $80^{\circ} \mathrm{C}$}

To simulate the precipitation mechanism with carbon dioxide gas $\left(\mathrm{CO}_{2}\right)$ injection in HSC 9.0, the software was programed to simulate a stepwise insertion of the gas with each step corresponding to the amount of $\mathrm{CO}_{2}$ added per minute for a rate of $\mathrm{CO}_{2}(\mathrm{~g})$ purging of $200 \mathrm{~mL} / \mathrm{min}$. The results of the simulation are depicted as speciation diagrams for the elements of interest, i.e., $\mathrm{Al}$ and $\mathrm{Na}$. As it can be seen in the $\mathrm{Al}$ speciation diagram (Fig. 3a), at $80{ }^{\circ} \mathrm{C}$ the main precipitate is dawsonite, a sodium alumino-carbonate phase, which forms even without $\mathrm{CO}_{2}(\mathrm{~g})$ addition because the solution is
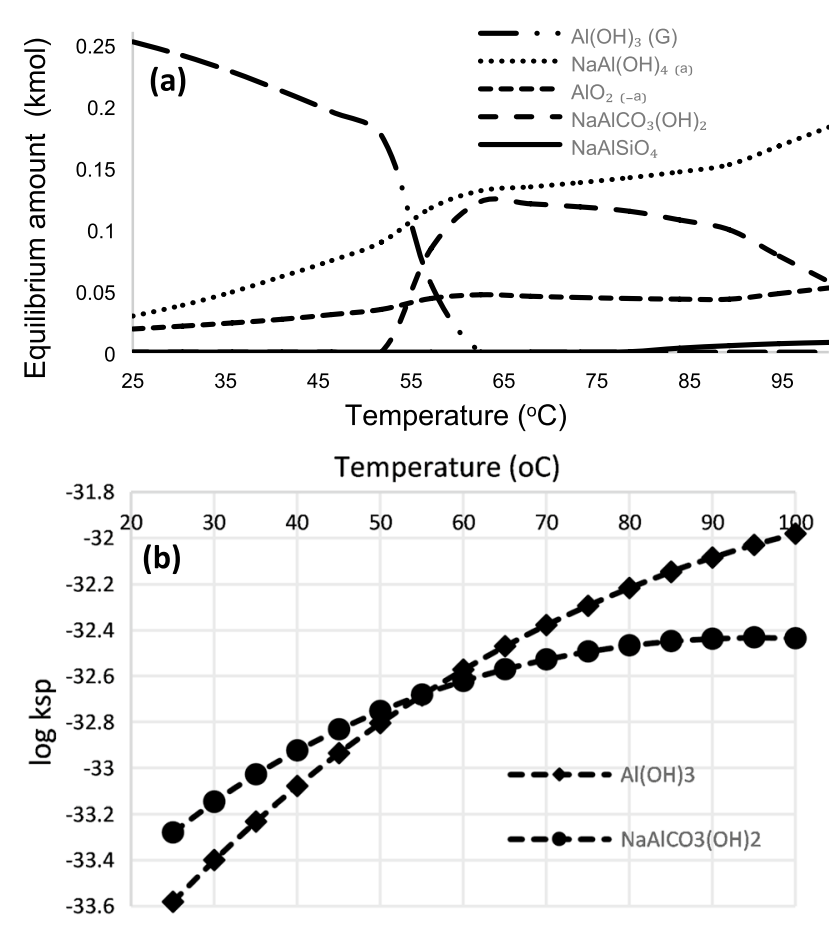

Fig. 2 a Aluminum speciation diagram of PLS, b Solubility product constant $\left(k_{\mathrm{sp}}\right)$ of aluminum hydroxide $\left(\mathrm{Al}(\mathrm{OH})_{3}\right)$ and dawsonite $\mathrm{NaAlCO}_{3}(\mathrm{OH})_{2}$ versus temperature. [where $\mathrm{a}=$ aqueous, $\mathrm{a}-$ aqueous anion, a+ aqueous cation]

supersaturated. The addition of $\mathrm{CO}_{2}(\mathrm{~g})$ increases the amount of $\mathrm{Al}$ precipitated as dawsonite and after 55 steps (cumulative addition of $0.49 \mathrm{~mol}$ of $\mathrm{CO}_{2}(\mathrm{~g})$ under standard conditions) the total amount of $\mathrm{Al}$ precipitates as dawsonite. This behavior is attributed to the high free carbonate ion content of the PLS [15], which shifts the equilibrium of the reaction (5) towards the right direction according to Le Chatelier's principle:

$\mathrm{Al}(\mathrm{OH})_{4}^{-}+\mathrm{NaHCO}_{3(\mathrm{aq})}=\mathrm{NaAl}(\mathrm{OH})_{(2)}\left(\mathrm{CO}_{3}\right)_{(s)}+\mathrm{OH}^{-}+\mathrm{H}_{2} \mathrm{O}$

This was expected above $65^{\circ} \mathrm{C}$, as seen in Fig. $2 \mathrm{~b}$, where the solubility product constant $\left(k_{\mathrm{sp}}\right)$ of dawsonite is lower than that of gibbsite.

\section{Carbonation Study of PLS at $40^{\circ} \mathrm{C}$}

For the carbonation simulation at $40{ }^{\circ} \mathrm{C}$ with HSC 9.0, the same parameters were used as with the simulation at $80^{\circ} \mathrm{C}$. It can be observed in the $\mathrm{Al}$ speciation diagram of Fig. $4 \mathrm{a}$ that $\mathrm{Al}(\mathrm{OH})_{3}$ is initially precipitated reaching $83 \%$ recovery after 20 steps (cumulative addition of $0.18 \mathrm{~mol}$ of $\mathrm{CO}_{2}(\mathrm{~g})$ under standard conditions). With the progression of carbonation, gibbsite is transformed to dawsonite reaching an 
(a)

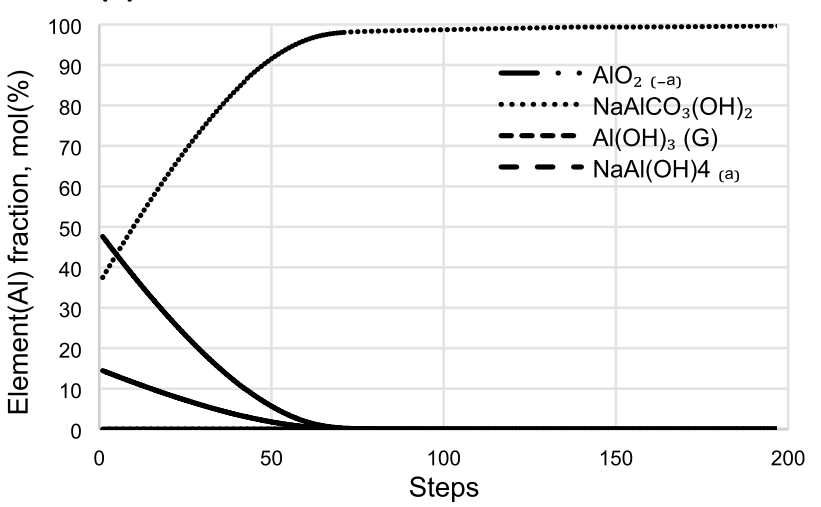

(b)

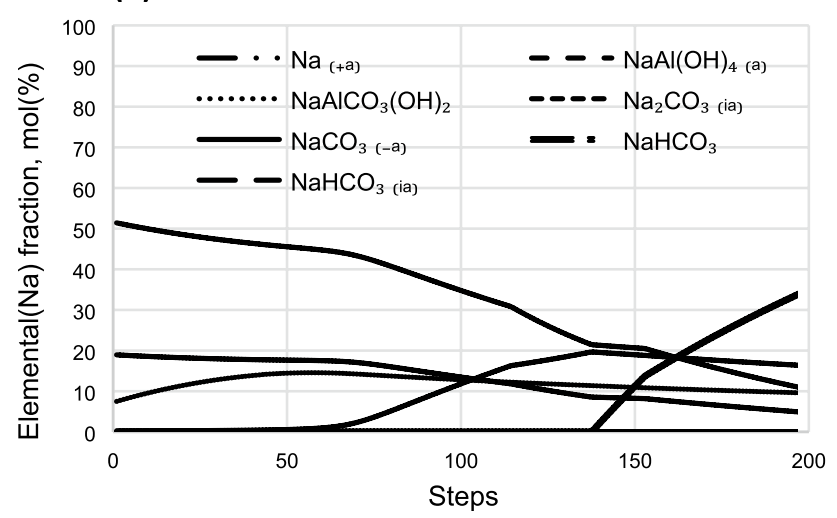

Fig. 3 Carbonation simulation of PLS at $80{ }^{\circ} \mathrm{C}$ with $200 \mathrm{~mL} / \mathrm{min} \mathrm{CO}_{2}$ injection-PLS speciation diagram of a aluminum, $\mathbf{b}$ sodium. [where $\mathrm{a}=$ aqueous, $\mathrm{a}-$ aqueous anion, $\mathrm{a}+$ aqueous cation]

aluminum recovery, in the form of dawsonite, of $100 \%$, after 55 steps (cumulative addition of $0.49 \mathrm{~mol}$ of $\mathrm{CO}_{2}(\mathrm{~g})$ under standard conditions) of carbonation.

\section{Experimental Verification of Carbonation Study of PLS}

To verify the thermodynamic analysis, experiments were performed at 80 and $40{ }^{\circ} \mathrm{C}$. For the $80{ }^{\circ} \mathrm{C}$ experiment, the experimental conditions were as follows: $200 \mathrm{~mL} / \mathrm{min}$ $\mathrm{CO}_{2}$ addition, 130-min $\mathrm{CO}_{2}$ purging (cumulative addition of $1.16 \mathrm{~mol}$ of $\mathrm{CO}_{2}(\mathrm{~g})$ under standard conditions), and no aging. Figure 5a presents the XRD analysis of the precipitate which shows that dawsonite is formed as the thermodynamic analysis had predicted. AAS analysis of the remaining solution after precipitation shows that $100 \%$ of $\mathrm{Al}$ is precipitated and $59.8 \%$ of $\mathrm{Si}$.

For the $40{ }^{\circ} \mathrm{C}$ experiment, the experimental conditions were as follows: $200 \mathrm{~mL} / \mathrm{min} \mathrm{CO}_{2}$ addition, 20-min $\mathrm{CO}_{2}$ purging (cumulative addition of $0.18 \mathrm{~mol}$ of $\mathrm{CO}_{2}(\mathrm{~g})$ under standard conditions), and no aging. Then, an experiment with
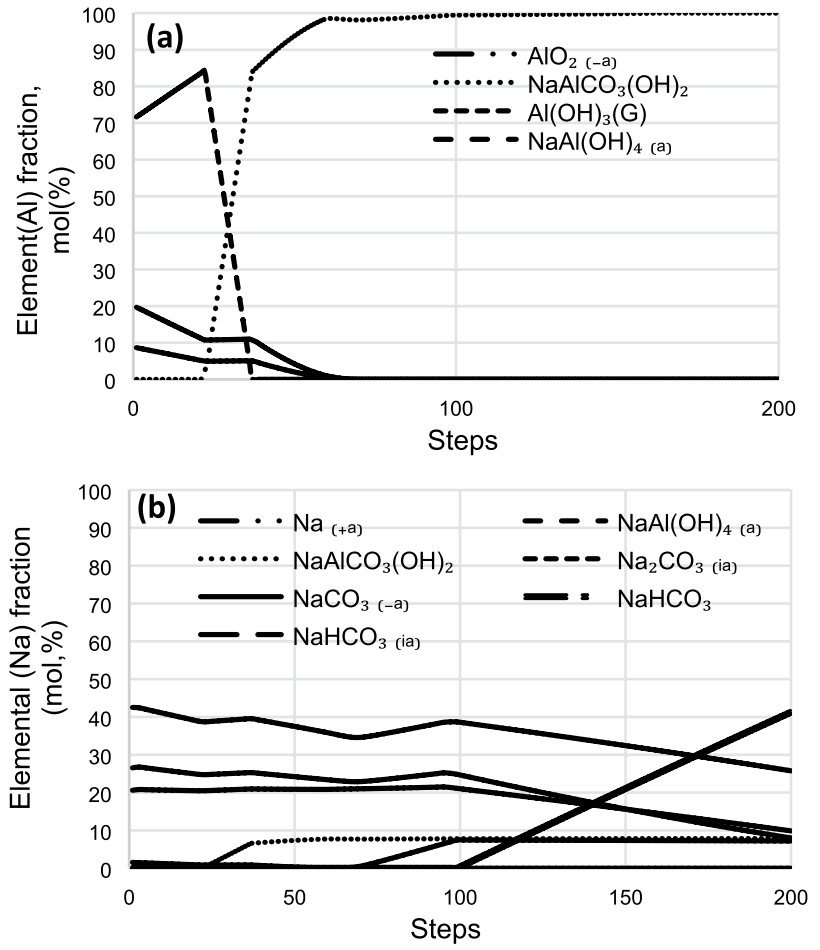

Fig. 4 Carbonation simulation of PLS at $40{ }^{\circ} \mathrm{C}$ with $200 \mathrm{~mL} / \mathrm{min} \mathrm{CO}_{2}$ injection-PLS speciation diagram of a aluminum, $\mathbf{b}$ sodium. [where $\mathrm{a}=$ aqueous, $\mathrm{a}-$ aqueous anion, $\mathrm{a}+$ aqueous cation]

$60 \mathrm{~min}$ of aging time was performed. Without aging no precipitation took place. With aging for $60 \mathrm{~min}$, a very small amount of precipitate was obtained and XRD analysis could not be conducted. Thus, FTIR analysis is presented in Fig. 5b, which shows that the main phase is dawsonite [16-21] with a very small amount of boehmite. This result indicates that during carbonation at $40{ }^{\circ} \mathrm{C}$ of PLS there is an initial stage (first 20 min or cumulative addition of $0.18 \mathrm{~mol}^{\circ} \mathrm{CO}_{2}(\mathrm{~g})$ under standard conditions) where practically no precipitation is taking place and neither Gibbsite (as the thermodynamic analysis predicted) or dawsonite are formed. Aging pushes gradually and slowly the system towards dawsonite formation.

The $\mathrm{Al}$ speciation diagram of the LCS (Fig. $6 \mathrm{a}$ ), at $80^{\circ} \mathrm{C}$, indicates that in an initial stage almost $62 \%$ of $\mathrm{Al}$ precipitates as gibbsite, and then it is transformed to dawsonite. Under the conditions where gibbsite is precipitated, there is no soda removal (Fig. 6b). At $40{ }^{\circ} \mathrm{C}$, the speciation diagram of $\mathrm{Al}$ (Fig. 6c) indicates that $96 \%$ of $\mathrm{Al}$ is precipitated as gibbsite and then it is transformed to dawsonite. Again, under the conditions where gibbsite is precipitated, there is no soda removal (Fig. 6d), cases which show a good chance to precipitate pure gibbsite. Additionally, the decrease of temperature makes wider the window in which alumina hydrates are potentially precipitated. In general, the simulations on both temperatures show that gibbsite can be precipitated. The 

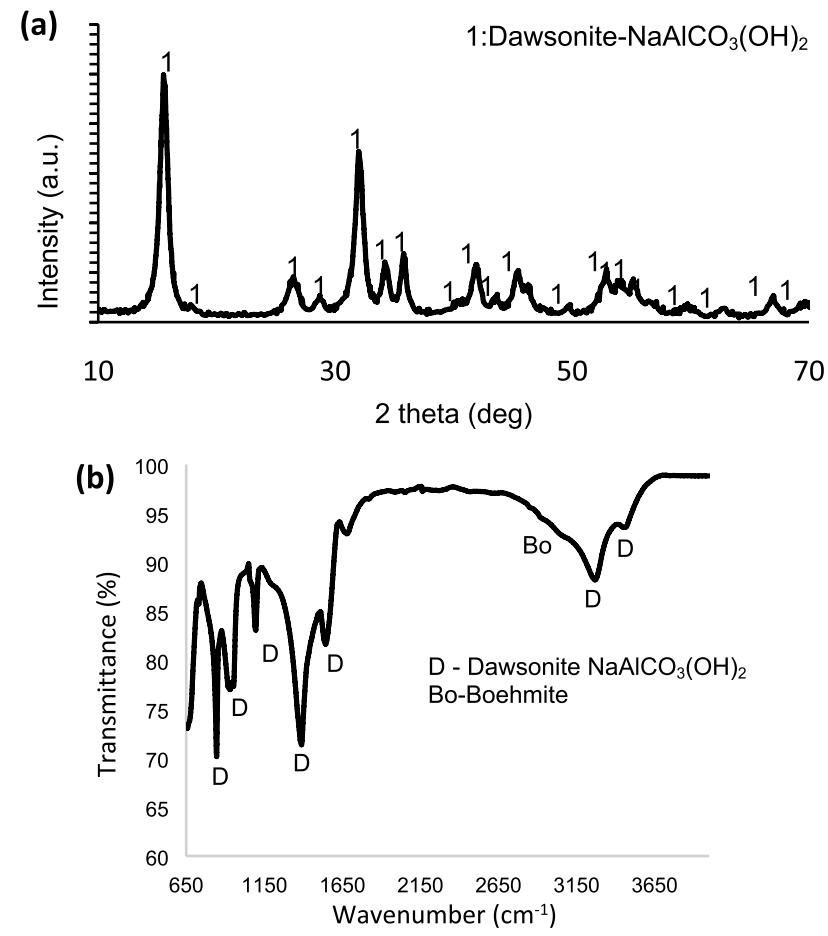

Fig. 5 a XRD of precipitate at $80{ }^{\circ} \mathrm{C}, 200 \mathrm{~mL} / \mathrm{min} \mathrm{CO}_{2}$ addition, 130-min $\mathrm{CO}_{2}$ purging, no aging, b FTIR of precipitate at $40{ }^{\circ} \mathrm{C}$, $200 \mathrm{~mL} / \mathrm{min} \mathrm{CO}_{2}$ addition, 20-min $\mathrm{CO}_{2}$ purging, 1-h aging. Thermodynamic analysis of low carbonate solution (LCS)

preferable conditions seem to be $40{ }^{\circ} \mathrm{C}$ where more than $95 \%$ of the aluminum can be recovered compared to $65 \%$ at $80^{\circ} \mathrm{C}$.

\section{Experimental Verification of Results of Low Carbonate Solution}

A precipitation experiment at $80{ }^{\circ} \mathrm{C}$ with $200 \mathrm{~mL} / \mathrm{min} \mathrm{CO}_{2}$ addition for 20-min $\mathrm{CO}_{2}$ purging (cumulative addition of $0.18 \mathrm{~mol}$ of $\mathrm{CO}_{2}(\mathrm{~g})$ under standard conditions) was performed. To push the system closer to the equilibrium state under those conditions 1-h aging period after the end of $\mathrm{CO}_{2}(\mathrm{~g})$ purging was applied. For the experimental study of our system, at $40{ }^{\circ} \mathrm{C}$ the following conditions were selected: $40{ }^{\circ} \mathrm{C}, 200 \mathrm{~mL} / \mathrm{min} \mathrm{CO}_{2}$ addition, 30-min $\mathrm{CO}_{2}$ purging (cumulative addition of $0.27 \mathrm{~mol}$ of $\mathrm{CO}_{2}(\mathrm{~g})$ under standard conditions). To push the system closer to the equilibrium state under those conditions, 1-h aging period after the end of $\mathrm{CO}_{2}(\mathrm{~g})$ purging was applied.

Figure 7a depicts the XRD analysis of the precipitate at $80^{\circ} \mathrm{C}$, which results in the precipitation of a mixture of dawsonite, bayerite, and boehmite. Nanocrystalline boehmite is the main phase followed by a substantially lower amount of dawsonite and traces of bayerite. Thermodynamic analysis under the same conditions predicted that alumina hydrates

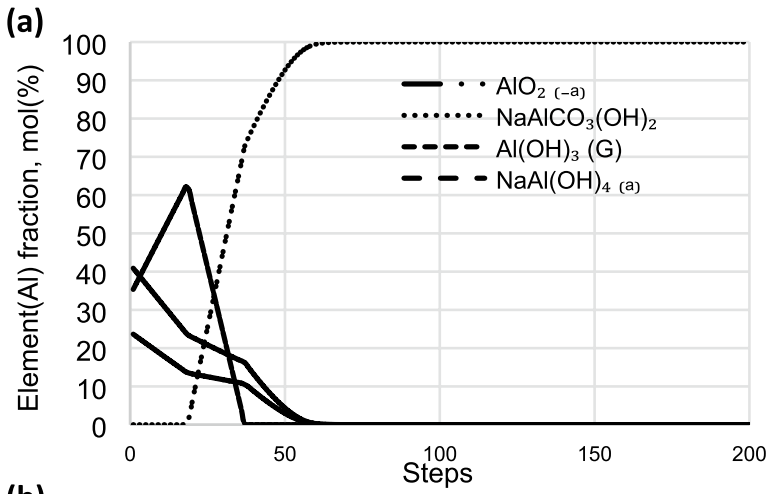

(b)

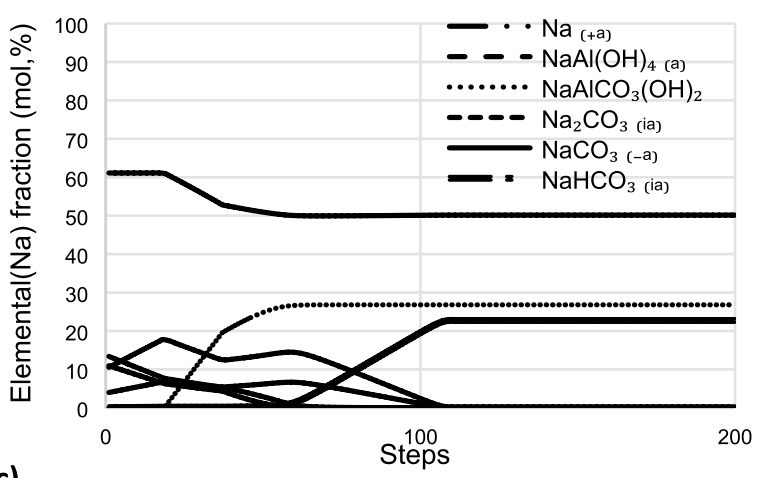

(c)
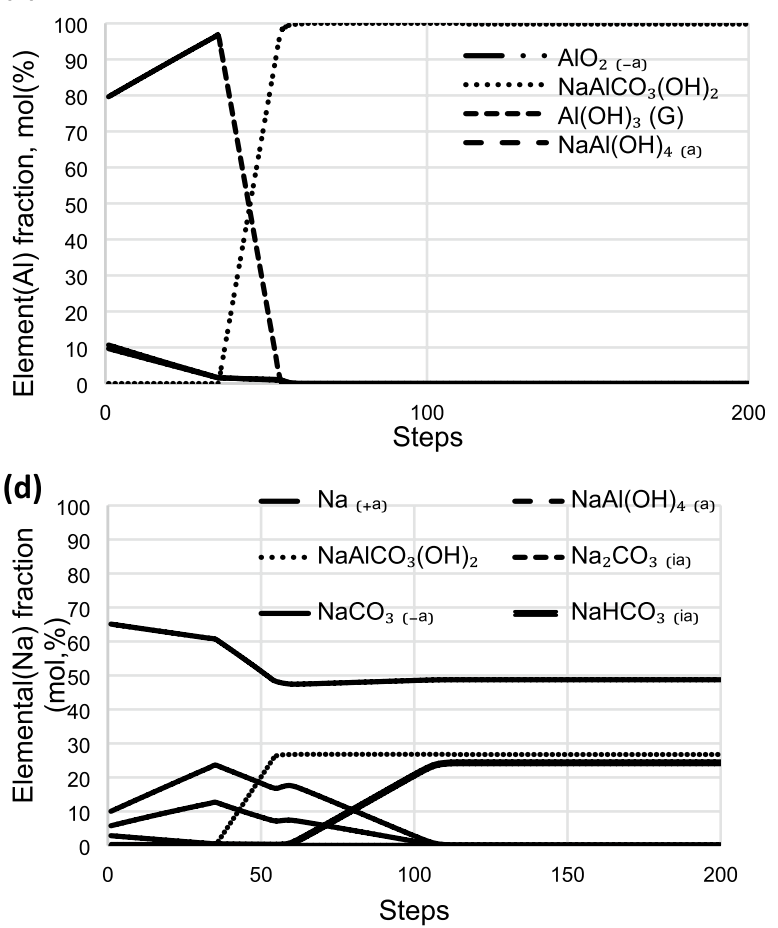

Fig. 6 Carbonation simulation of PLS with $200 \mathrm{~mL} / \mathrm{min} \mathrm{CO}_{2}$ injection-PLS speciation diagram of a aluminum at $80{ }^{\circ} \mathrm{C}$, b sodium at $80{ }^{\circ} \mathrm{C}$, c aluminum at $40{ }^{\circ} \mathrm{C}, \mathbf{d}$ sodium at $40{ }^{\circ} \mathrm{C}$. [where a $=$ aqueous, $\mathrm{a}-$ aqueous anion, $\mathrm{a}+$ aqueous cation]

(gibbsite) and dawsonite would be the precipitated phases, something that is in partial agreement with the experimental results as the main alumina hydrate precipitate phase is 


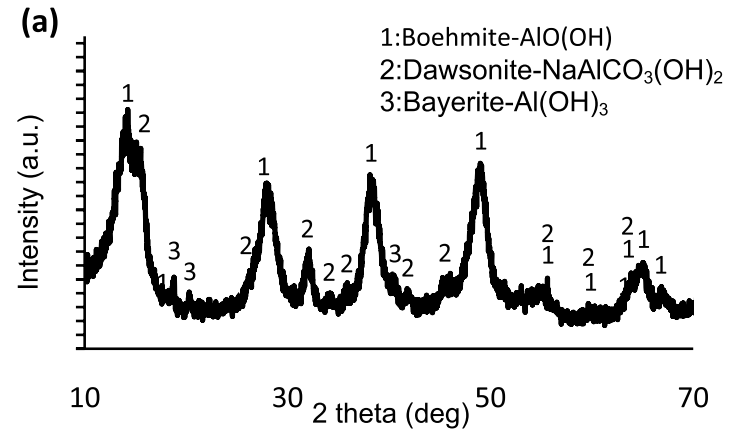

(b)

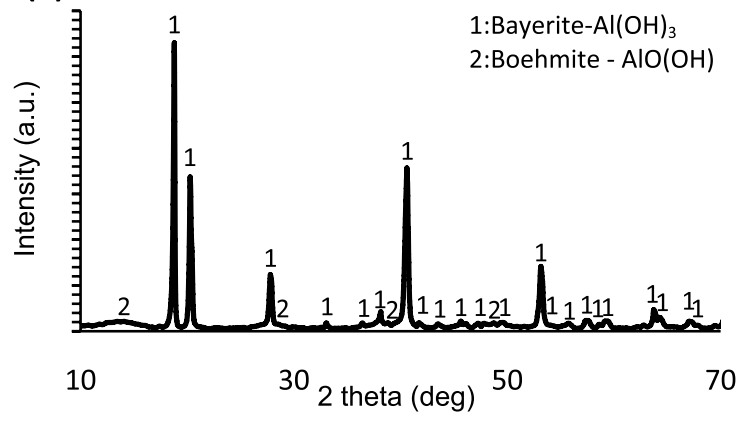

Fig. 7 a XRD of precipitate at $80{ }^{\circ} \mathrm{C} .200 \mathrm{~mL} / \mathrm{min} \mathrm{CO}_{2}$ addition, 20-min $\mathrm{CO}_{2}$ purging, 1-h aging period $\mathbf{b} \mathrm{XRD}$ of precipitate at $40{ }^{\circ} \mathrm{C}$. $200 \mathrm{~mL} / \mathrm{min} \mathrm{CO}_{2}$ addition, 30-min $\mathrm{CO}_{2}$ purging, 1-h aging period

boehmite with traces of bayerite which is an allotropic form of gibbsite.

Figure $7 \mathrm{~b}$, illustrates the XRD analysis of the precipitate at $40{ }^{\circ} \mathrm{C}$, which is a mixture of crystalline bayerite as the main phase and amorphous boehmite or pseudo-boehmite as a minor phase. Dawsonite was not detected. The results are again in partial agreement with the thermodynamic analysis which predicts under the same conditions the formation of alumina trihydrate in the form of gibbsite without the presence of boehmite. To understand the boehmite formation, both the experiments were repeated but this time no aging period was applied. The XRD results showed the precipitation of only pseudo-boehmite in both the experiments (Fig. 8).

According to the thermodynamic analysis, gibbsite should be the thermodynamically favored alumina hydrate phase but instead, boehmite was precipitated. The experimental observations can be explained by the current knowledge on alumina hydrates precipitation from aluminate solutions [22]. As the bubbles of $\mathrm{CO}_{2}$ gas are added in the highly alkaline sodium aluminate/sodium carbonate solution, neutralization of hydroxide ions occurs and thus the solution $\mathrm{pH}$ is gradually decreased. Locally, in the area around the $\mathrm{CO}_{2}$ gas bubbles (Fig. 9), a condition of a very sharp pH gradient is established due to local high acidity imposed by the $\mathrm{CO}_{2}(\mathrm{~g})$ dissolution. Under that conditions, the formation of

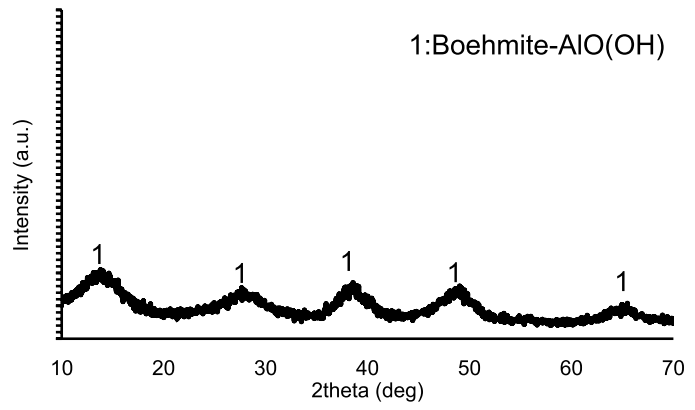

Fig. $8 \mathrm{XRD}$ of precipitate at $80{ }^{\circ} \mathrm{C} .200 \mathrm{~mL} / \mathrm{min} \mathrm{CO}_{2}$ addition, 20-min $\mathrm{CO}_{2}$ purging

metastable pseudo-boehmite (Eq. 6) as is shown in previous work [23] takes place.

$\mathrm{Al}(\mathrm{OH})_{4(\mathrm{aq})}^{-}+\mathrm{H}_{(\mathrm{aq})}^{+}=\mathrm{AlOOH}_{(\mathrm{am})}+2 \mathrm{H}_{2} \mathrm{O}_{(\mathrm{l})}$

Then, during aging, as the bulk solution is alkaline, the metastable boehmite starts its transformation to the stable alumina trihydrate phase which seems to be bayerite instead of gibbsite. This has also been observed in other research groups [24, 25].

\section{Conclusions}

Theoretical modeling of an aluminate PLS, originating from calcium aluminate slag leaching with $\mathrm{Na}_{2} \mathrm{CO}_{3}$, showed that according to the $k_{\mathrm{sp}}$ of gibbsite and dawsonite, gibbsite is spontaneously precipitated below $65^{\circ} \mathrm{C}$ and dawsonite over $65{ }^{\circ} \mathrm{C}$. Modeling a carbonation process for the PLS showed that at $80{ }^{\circ} \mathrm{C}$, dawsonite should be precipitated, which was also proven experimentally. At $40^{\circ} \mathrm{C}$, according to the thermodynamic modeling of the carbonation, gibbsite should initially precipitate.

The experiments though showed that only dawsonite with a small amount of boehmite is precipitated. In general, the PLS produced seems to be unsuitable for the precipitation of alumina hydrate phases due to its high sodium carbonate content.

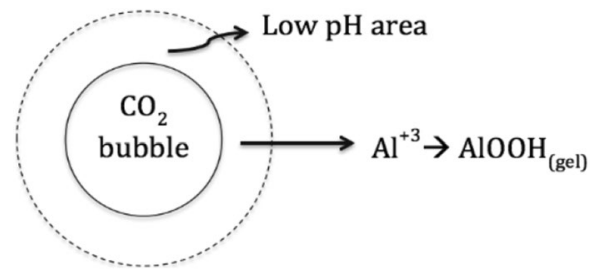

Fig. 9 Schematic representation of boehmite precipitation 
The simulation of the carbonation of the LCS suggested that both at $80{ }^{\circ} \mathrm{C}$ and $40{ }^{\circ} \mathrm{C}$, during the first stages of carbonation gibbsite is precipitated, while experimentally, pseudo-boehmite was precipitated. Boehmite occurrence was credited to the very low $\mathrm{pH}$ areas generated instantly around the $\mathrm{CO}_{2}$ gas bubbles.

Later, since the bulk solution is alkaline, during aging the metastable boehmite starts its transformation to the stable alumina trihydrate phase, which is bayerite.

It was verified that the very high carbonate content of the initial PLS was the reason only dawsonite could be precipitated out and that if the favorable precipitate is alumina hydrate, then the carbonate content should be carefully monitored in the leaching stage to keep the concentration of the free carbonate ions as low as possible.

Acknowledgements The research leading to these results has received funding from the European Community's Horizon 2020 Programme (H2020/2014-2020) under Grant Agreement No. 767533. This publication reflects only the author's view, exempting the Community from any liability. Project website: https://www.ensureal.com/

\section{Declarations}

Conflict of interest On behalf of all authors, the corresponding author states that there is no conflict of interest.

Open Access This article is licensed under a Creative Commons Attribution 4.0 International License, which permits use, sharing, adaptation, distribution and reproduction in any medium or format, as long as you give appropriate credit to the original author(s) and the source, provide a link to the Creative Commons licence, and indicate if changes were made. The images or other third party material in this article are included in the article's Creative Commons licence, unless indicated otherwise in a credit line to the material. If material is not included in the article's Creative Commons licence and your intended use is not permitted by statutory regulation or exceeds the permitted use, you will need to obtain permission directly from the copyright holder. To view a copy of this licence, visit http://creativecommons.org/licenses/by/4.0/.

\section{References}

1. Miller J, Irgens A (2016) Alumina production by the pedersen process-History and future. In: Donaldson D, Raahauge BE (eds) Essential readings in light metals. Springer International Publishing, Cham, pp 977-982

2. Vafeias M, Marinos D, Panias D, Safarian J, Van Der Eijk C, Solhem I, Balomenos E, Ksiazek M, Davris P (2018) From red to grey: revisiting the Pedersen process to achieve holistic bauxite ore utilisation. In Proceedings of the 2 nd international bauxite residue valorisation and best practices conference Athens, Greece. Accessed 7 to 10 May 2018, pp 111-117.

3. Nielsen K (1978) The Pedersen process - An old process in a new light. Erzmetall 31:523-525

4. Aktieselskapet Norsk Aluminium. Process for the manufacture of aluminium oxide. 252399, 9/06 1927.

5. Pedersen H. Process of manufacturing aluminum hydroxide. US Patent 1618105, Accessed 15 Feb 1927.
6. Wang Z, Yang L, Zhang J, Guo Z-C, Zhang Y (2010) Adjustment on gibbsite and boehmite co-precipitation from supersaturated sodium aluminate solutions. Trans Nonferrous Metals Soc China 20:521-527. https://doi.org/10.1016/s1003-6326(09) 60172-2

7. Li Y, Zhang Y, Yang C, Zhang Y (2009) Precipitating sandy aluminium hydroxide from sodium aluminate solution by the neutralization of sodium bicarbonate. Hydrometallurgy 98:5257. https://doi.org/10.1016/j.hydromet.2009.03.011

8. Safarian J, Kolbeinsen L (2016) Sustainability in alumina production from bauxite. In Proceedings of the 2016 sustainable industrial processing summit and exhibition, Flogen.

9. Zhou Q, Peng D, Peng Z, Liu G, Li X (2009) Agglomeration of gibbsite particles from carbonation process of sodium aluminate solution. Hydrometallurgy 99:163-169. https://doi.org/10. 1016/j.hydromet.2009.07.015

10. Lee M-Y, Parkinson GM, Smith PG, Lincoln FJ, Reyhani MM (1997) Characterization of aluminum trihydroxide crystals precipitated from caustic solutions. Separ Purif Crystal 667:123-133

11. Besida J, van Emden B (2008) Increasing alumina precipitation yield using soda control. Proceedings of the 8th international alumina quality workshop, pp 351-354.

12. Thomson MR, McLeod HMJ, Skow ML (1949) Recovery of alumina from submarginal bauxites - Part 2. - Extraction of alumina from electric-furnace slags of calcium aluminate; United States department of the interior - Bureau of mines: Alaska Branch.

13. Sipos P (2009) The structure of Al(III) in strongly alkaline aluminate solutions-A review. J Mol Liq 146:1-14. https://doi. org/10.1016/j.molliq.2009.01.015

14. McCoy BN, Dewey JL (2016) Equilibrium composition of sodium aluminate liquors. In: Donaldson D, Raahauge BE (eds) Essential readings in light metals: volume 1 alumina and bauxite. Springer International Publishing, Cham, pp 148-154

15. Aghazadeh V, Shayanfar S, Samiee Beyragh A (2019) Thermodynamic modeling and experimental studies of bayerite precipitation from aluminate solution: temperature and $\mathrm{pH}$ effect. Iran J Chem Chem Eng 38:229-238. https://doi.org/10.30492/ijcce. 2019.30926

16. Serna CJ, García-Ramos JV, Peña MJ (1985) Vibrational study of dawsonite type compounds $\mathrm{MAl}(\mathrm{OH})_{2} \mathrm{CO}_{3}(\mathrm{M}=\mathrm{Na}, \mathrm{K}$, NH4). Spectrochim Acta Part A 41:697-702. https://doi.org/ 10.1016/0584-8539(85)80177-X

17. Frueh AJ, Golightly JP (1967) The crystal structure of dawsonite $\mathrm{NaAl}\left(\mathrm{CO}_{3}\right)(\mathrm{OH})_{2}$. Can Mineral 9:51-56

18. Álvarez-Ayuso E, Nugteren HW (2005) Synthesis of dawsonite: A method to treat the etching waste streams of the aluminium anodising industry. Water Res 39:2096-2104. https://doi.org/ 10.1016/j.watres.2005.03.017

19. Su C, Suarez DL (1997) In situ infrared speciation of adsorbed carbonate on aluminum and iron oxides. Clays Clay Miner 45:814-825. https://doi.org/10.1346/CCMN.1997.0450605

20. Lee DH, Condrate RA (1995) An FTIR spectral investigation of the structural species found on alumina surfaces. Mater Lett 23:241-246. https://doi.org/10.1016/0167-577X(95)00039-9

21. Frederickson LD (1954) Characterization of hydrated aluminas by infrared spectroscopy. Anal Chem 26:1883-1885. https://doi. org/10.1021/ac60096a007

22. Panias D, Krestou A (2007) Effect of synthesis parameters on precipitation of nanocrystalline boehmite from aluminate solutions. Powder Technol 175:163-173. https://doi.org/10.1016/j. powtec.2007.01.028

23. Panias D, Paspaliaris I (1998). Precipitation of boehmite - An innovative route in the alumina production. 
24. Li H, Addai-Mensah J, Thomas JC, Gerson AR (2005) The crystallization mechanism of $\mathrm{Al}(\mathrm{OH})_{3}$ from sodium aluminate solutions. J Cryst Growth 279:508-520. https://doi.org/10.1016/j. jerysgro.2005.02.019

25. Bradley SM, Kydd RA, Howe RF (1993) The structure of Al gels formed through the base hydrolysis of $\mathrm{Al}^{3+}$ aqueous solutions. J Colloid Interface Sci 159:405-412. https://doi.org/10. 1006/jcis. 1993.1340

\section{Authors and Affiliations}

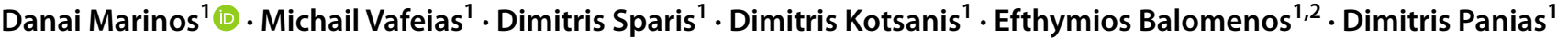

1 School of Mining and Metallurgical Engineering, National Technical University of Athens, 9 Iroon Polytechneiou str., Athens, Greece
Publisher's Note Springer Nature remains neutral with regard to jurisdictional claims in published maps and institutional affiliations.
Metallurgy Business Unit, Mytilinaios S.A., Agios Nikolaos, Voiotia, Greece 